\section{A symptom observation chart to support an individualised approach to care for dying patients in hospital}

From July 2013, the Liverpool Care Pathway for dying patients was gradually withdrawn in response to an independent review. ${ }^{1}$ Since this time, there has been a necessary progression towards providing more individualised care to patients in the final hours and days of life. Initially, this was shaped by the Leadership Alliance for the Care of Dying People, whose publication One chance to get it right ${ }^{2}$ brought focus to five key priorities for the care of such patients. With this timely shift, healthcare professionals developed local practices to support the implementation of this improved approach. The last 2 months have seen the publication of the Royal College of Physicians' acute care resource: End-of-life care in the acute setting $^{3}$ and the National Institute for Health and Care Excellence guidance: Care of dying adults in the last days of life. ${ }^{4}$ As such, the blueprint for how the treatment and care of all dying patients should be approached has become firmly laid down.

We hereby write to share a local initiative developed and used to support this process: a 'symptom observation chart for the dying patient'. Developed in the acute setting, this chart (with accompanying guidance) is employed once a patient is recognised as dying. Analogous to a National Early Warning Score chart in format, it has been adopted easily by the multiprofessional team. Its purpose is to:

$>$ facilitate the regular and standardised assessment of patient comfort

> create a record of symptom control over time, which can help inform necessary adjustments to the individualised care plan

$>$ encourage communication between members of the multiprofessional team by, for example, providing a clear framework for escalating and requesting urgent medical review if symptoms are not controlled by the existing care plan

$>$ contribute to the quality assessment of care provided to dying patients

$>$ support education of the multiprofessional team, enabling continued improvement to the care of dying patients.

Shortly after the introduction of the chart, a questionnaire survey of 135 healthcare professionals was conducted. This demonstrated that $97 \%$ found the chart user-friendly;
$87 \%$ felt it facilitated communication between members of the multiprofessional team; $83 \%$ felt it prompted earlier intervention from doctors for symptom control; $91 \%$ felt that it improved the symptom assessment of dying patients; and $86 \%$ of nurses found it assisted them in knowing when to request additional patient review by a doctor. Finally, $87 \%$ felt it contributed to improvements in the overall care of dying patients.

The chart has also been adopted for use in the local health economy by primary care nursing teams and within care homes with nursing. Other tertiary hospitals that have embraced the chart have found it beneficial, with more detailed evaluation anticipated. Given that optimal symptom control in dying people is paramount, we believe that such a chart is of significant value in supporting the multiprofessional team to maintain a patient's comfort and dignity.

\section{Acknowledgements}

We would like to thank the BSUH End of Life Care Steering Group, particularly Ms Karen Carroll and Dr Neha Varma who, together with the authors of this letter, devised and developed the chart; Dr Max Cooper and Dr Ambre Doherty (Brighton and Sussex Medical School) for their contribution to the chart's evaluation.

LOUISE D MASON

Consultant in palliative medicine, Department of Palliative Care, Sussex Cancer Centre, Brighton and Sussex University Hospitals NHS Trust, Brighton, UK

LAUREN Z WATERMAN SHO in psychiatry, Priory Hospital, London, UK

\section{References}

1 Neuberger J. More care less pathway: a review of the Liverpool Care Pathway. London: DoH, 2013.

2 Leadership Alliance for the Care of Dying People. One chance to get it right: improving people's experience of care in the last few days and hours of life. London: DoH, 2014.

3 Royal College of Physicians. Acute care resource 14: end-of-life care in the acute seeing. London: RCP, 2015.

4 National Institute for Health and Care Excellence. Clinical guidelines for care of the dying adult in the last days of life (NG31). London: NICE, 2015. 
Symptom Observation

Chart for the

Dying Patient

Date patient was recognised as dying:
Brighton and Sussex W/HS University Hospitals

NHS Trust

Record observations at least 4 hourly

\section{Patient name:}

Hospital No:

NHS No.

D.O.B:
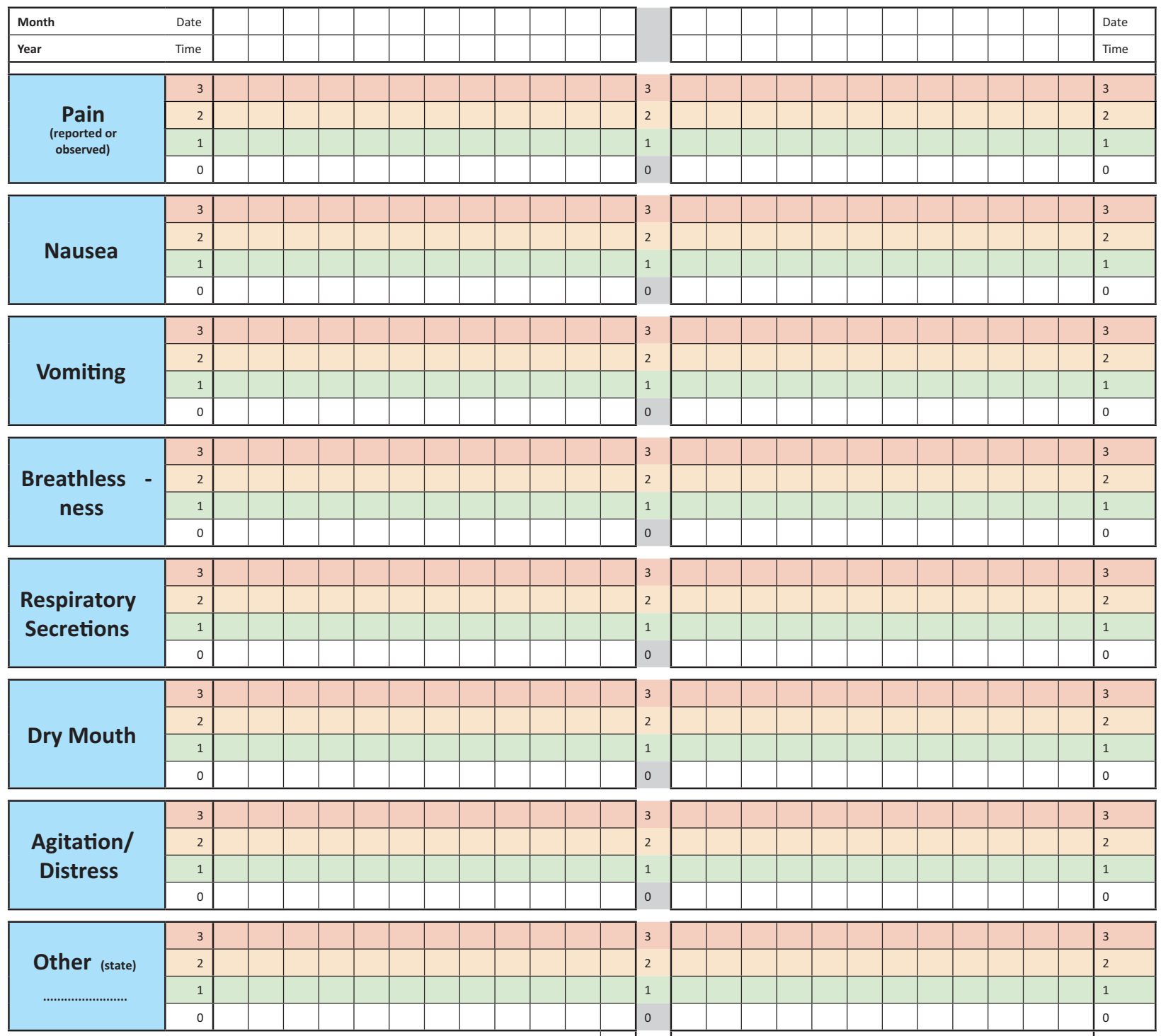

\begin{tabular}{|l|}
\hline HCA signature \\
\hline $\begin{array}{l}\text { Registered nurse } \\
\text { signature }\end{array}$ \\
\hline Doctor signature \\
\hline
\end{tabular}
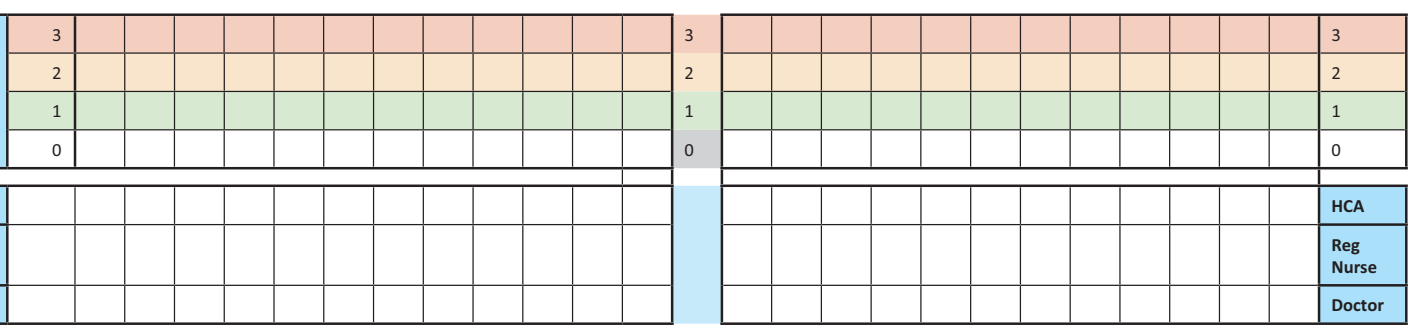

\begin{tabular}{|l}
\hline $\begin{array}{l}3=\text { Symptom present, does not resolve with PRN } \\
\text { medication }\end{array}$ \\
\hline $\begin{array}{l}2 \text { = Symptom present, requires PRN medication to } \\
\text { resolve }\end{array}$ \\
\hline $1=$ Symptom present, resolves spontaneously \\
\hline $0=$ Symptom absent \\
\hline
\end{tabular}

Urgent doctor review of patient and care plan is required for any single symptom score of 3

Care plan continues. If 3 consecutive symptom scores of 2 are present (for any symptom), urgent doctor review of patient and care plan is required

Care plan continues, consider if adaptions may be required Care plan continues 